\title{
AN ECONOMIC IMPACT OF SUBSIDIZED BREAD AFTER BAKING APPLICATION SYSTEM IN GHARBIA GOVERNORATE
}

\author{
MUSTAFA, A. RIZK, A. A. RAOUF ELDOKLA, \\ M. A. EL SAWY and M. S. A. GHAZY \\ Agricultural Economics Research Institute, ARC, Dokki, Giza \\ (Manuscript received 16 August 2016)

\begin{abstract}
$\mathrm{T}$ he research aim to idenify the economic impcat of application the new system to distribute the subsidized bread to the consumers and the owners of the bakery, to achiveing that aim by studing the cost of production and the revenu befor and after that system in Gharbia governorate. The data obtained from a sample from the owners of the bakery during the year 2015 in Gharbia governorate.
\end{abstract}

\section{The most important results are:}

1.The cost of beacking one of flowr was, about 47.7, 48.1 pounds of balady bakeries and a half autamatic before application the new system respectively, while the total of those costs for bakeries developed 250 pounds. The cost of bag manufacturing after application to about 344.9, 338.8, 342.6 pounds for bakeries balady, half automatic and advanced.

2. Net revenue from bag manufacture of flour was about 7.3, 6.9, 12 pounds for three types of bakeries respectively befor the application, and rosed to 25.6, 31.2, 32.2 pounds for the three types of bakeries.

3. The average number of irregularities monthly reached by the application amounted to about $9,7,3$ in baldy of the bakeries and half the mechanism and the mechanism developed, respectively, and then decreased after application to 4, 3, 2 in baldy of the bakeries and half the mechanism and the mechanism developed respectively.

4. The rising of production costs were the most important problems facing the owners of bakeries relative importance amounted to about $100 \%$, followed by the problem of the high value of irregularities, then the problem of low capacity and the amount of bread remain without distribution on the cards.

\section{Recommendation :}

1. A tighten control and continuous monitoring the owners of bakeries and pud a sever punishment for the irregularities.

2. Reappoint in the cost of production for one bag of flour for a period of time to to estimate the real cost of labor fuel, water, and electrictiy.

3. The points of bread in the cards have to review with the grocery to control the price of the commodities which he distribute and its amounts.

4. Establish offices to maintenance the cards of distribution and its communication to the internet. 


\title{
المردود الاقتصادى لتصنيع الخبز المدعم بعد تطبيق منظومة الخبز بمحافظة الغربية
}

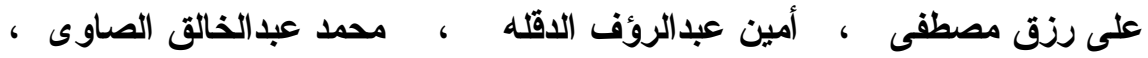 \\ محمد غازى سبد أحمد$$
\text { مركز البحوث الزراعية - معهد بحوث الاقتصاد الراعى - دقى - جيزة }
$$$$
\text { الملخص }
$$

استهاف البحث دراسة بعض الاثار الاقتصادية المترنبة على تطبيق منظومة الخبز من خلال مقارنة أهم المؤشرات الاقتصادية لتصنيع الخبز المدعم قبل وبعد نطبيق المنظومة بمحافظة الغربية، واعند البحث فى تحقيق أهدافه على اسلوب التحليل الإحصائى الوصفى ولاكمى للمتغيرات الاقتصادية حيث تم تقدير متوسط التكاليف والعائد لتصنيع الخبز المدعم قبل وبعد العمل بمنظومة الخبز، وقد اعتمد البحث على اليانات الخاصة بمديرية التموين بالغربية، والييانات الأولية التى تم الحصول عليها من عينة البحث و الممنلة لأصحاب المخابز للخبز المدعم قو امها جـ صاحب مخبز بمحافظة الغربية عام 0 ــr.

\section{أسفرت نتائج الار اسة عن مجموعة من الحقائق أهمها:}

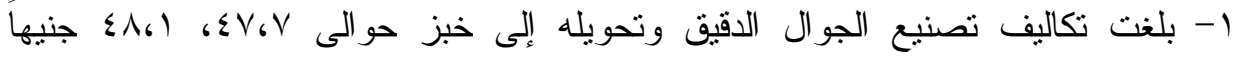
للمخابز البلاى ونصف الآلى قبل النطبيق على النرتيب، بينما بلغت تلك التكاليف بالنسبة للمخابز

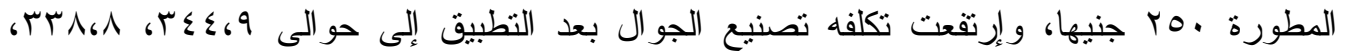

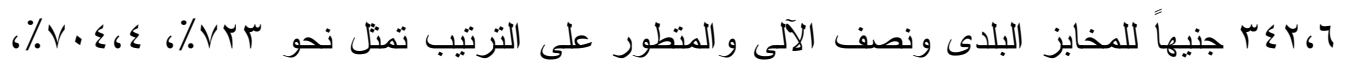

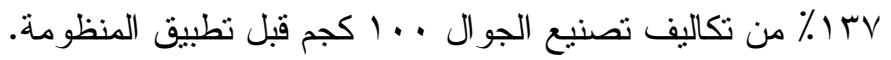

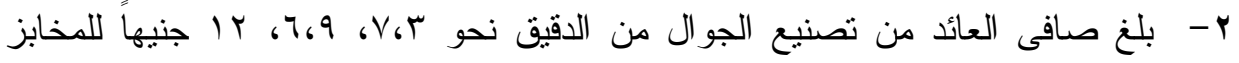

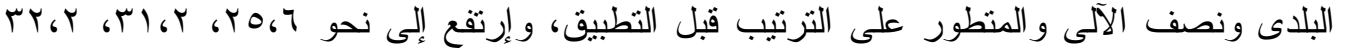

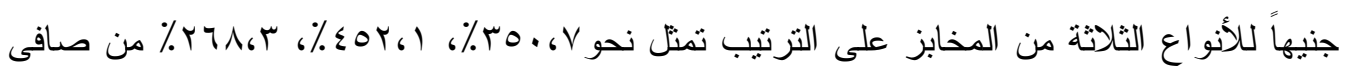
العائد على تصنيع الجو ال قبل تطبيق المنظومة.

r- بلغ متوسط عدد المخالفات الثهريه قبل نطبيق المنظومة نحو 9، V، ؟ مخالفة للمخابز

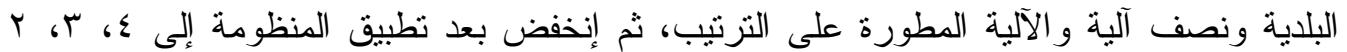
مخالفة للمخابز البلدية ونصف آلية والآلية المتطورة على الترتيب.

ع - تبين ارتفاع تكاليف الانتاج حيث كانت أهم المشاكل التى تو اجه اصحاب المخابز وبلغت

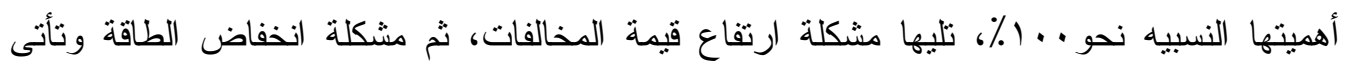
موخراً مشكلة تبقى كمية من الخبز دون توزيع على البطاقات.

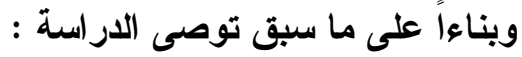
1 - نتشيد الرقابة على مكاتب التموين. 
ץ- اهتمام الثركات المسئولة عن نظام الكروت الذكية باستير اد آلات جيده لتفادى تعطيل النظام.

r- اعادة النظر فى التكلفة الفعلية للجو ال كل فترة من الزمن لمو اجهة ارتفاع اسعار العمالة و السو لار و الكهرباء و المياه وخلافه.

ع - وضع قو انين و اضحة لتنفيذ منظومة الخبر و عدم التلاعب بالدعم ووصولة ولى ولى المستحقين.

يعتبر الخبز أحد أهم المكونات على مائدة الطعام المصرية، حيث يعد من أرخص مصادر

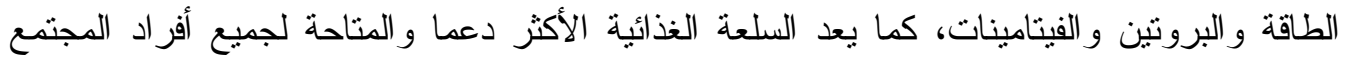
على الرغم من اختلاف دخولهم، كذلك فان الخبز المدعم لم يتغير سعره منذ عام 1919 و المحدد

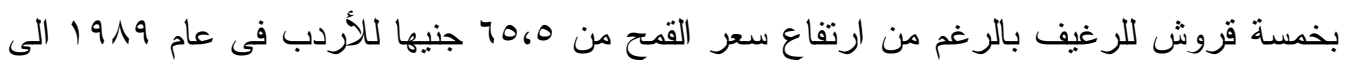

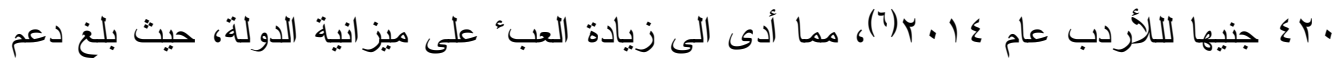

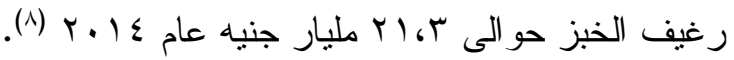

ونتير التقديرات الى ان منوسط استهلاك الفرد من القمح فى مصر بلغ حوالى هبا كيلو

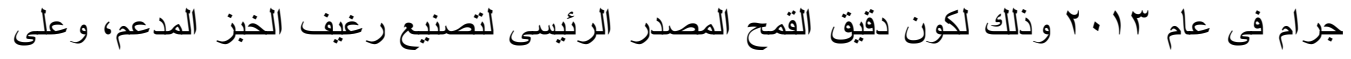

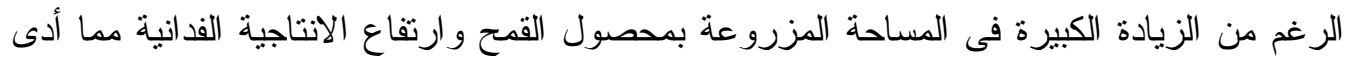

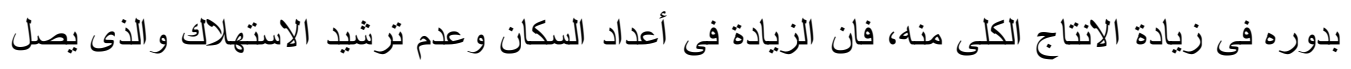

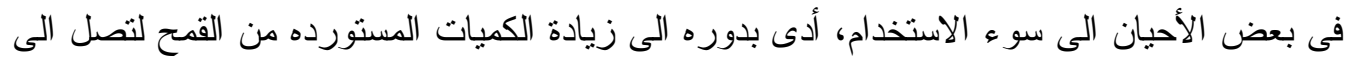

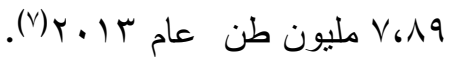

ومن الجدير بالذكر أن رغيف الخبز البلدى المدعم يُصنع من دقيق القمح استخر اج rي٪؛ ولقد واجه المواطنون العديد من المشاكل للحصول على رغيف الخبز المدعم، مما أدى الى قيام

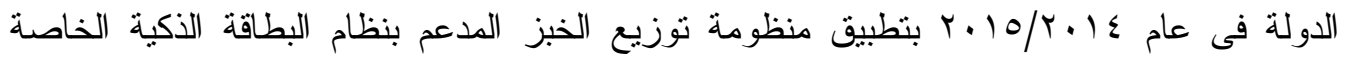
بصرف المقررات التموينية وذلك لضمان عدالة توزيع الخبز على المواطنين و العمل على ترشيد الاستهلاك من الخبز بصرف السلع مقابل فرق نقاط الخبز الذى لا يتم استهلاكه.

مشكلة البحث :

يمنل الدعم بصفة عامة عبئا ماديا على ميز انية الدولة، الا أن دعم رغيف الخبز بصفة خاصة يمنل

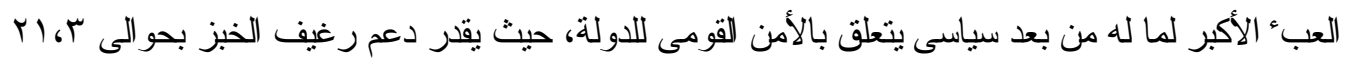

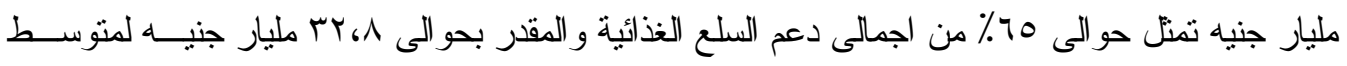

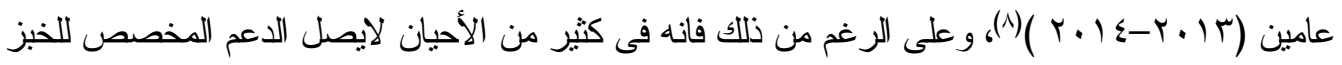

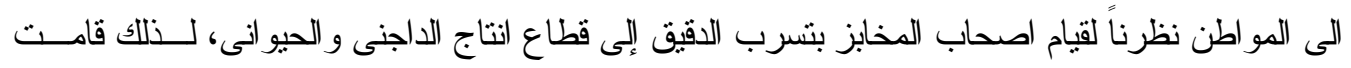
الدولة ممنلة فى وزارة التموين و التجارة الداخلية بتطبيق منظومة الخبز لتوزيع الخبز المدعم على المو اطنين

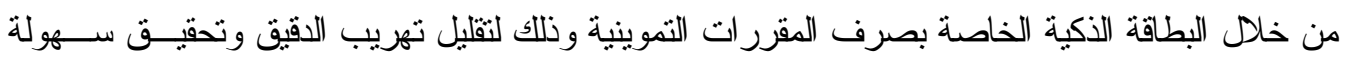




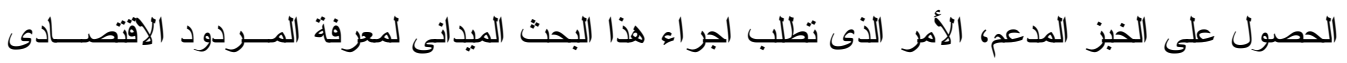
وتحديد أهم الاثار الاقتصادية لنطبيق منظومة الخبز على أصحاب المخابز.

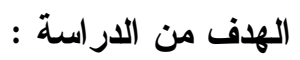

يهدف البحث در اسة بعض الاثار الاقتصادية المنرنبة على تطبيق منظومة الخبز من خلال مقارنة أهم المؤشرات الاقتصادية لتصنيع الخبز المدعم قبل وبعد تطبيق المنظومة بمحافظة الغربية من خلال الأهداف الفرعية التالية :

1- در اسة التكاليف و العائد لتصنيع الخبز المدعم قبل وبعد العمل بمنظومة الخبز . r- در اسة الاثار الاقتصادية لنطبيق منظومة الخبز على اصحاب المخابز و المو اطنين. r- در اسة سلوكيات اصحاب المخابز قبل وبعد تطبيق منظومة الخبز بمحافظة الغربية. ع - المشاكل النى تو اجه أصحاب المخابز بمحافظة الغربية . الاسلوب البحثى ومصادر البياتات :

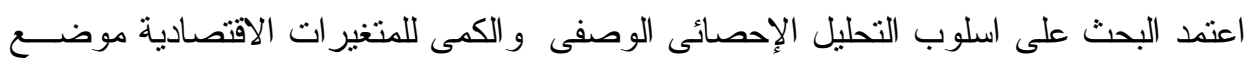

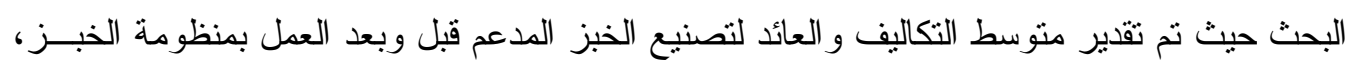

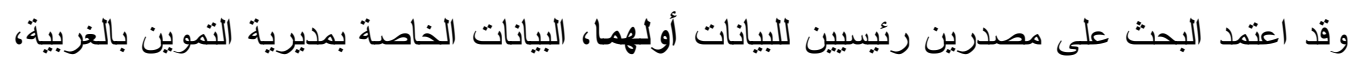

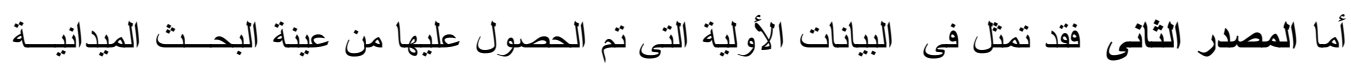
و الممتلة لأصحاب المخابز للخبز المدعم عام 10 ــ بمحافظة الغربية.

عينة البحث : نم إجر اء البحث الميدانى بمحافظة الغربية عام 10 ـr، حيث تم إختيار العينة مسن

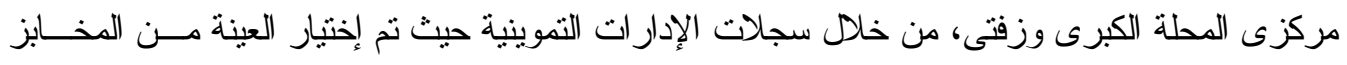

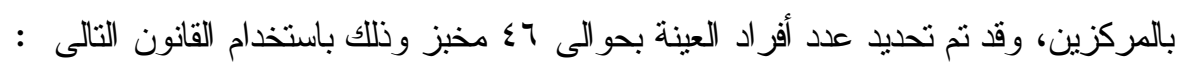

$n=\frac{t^{2} \sigma^{2} N}{\Delta^{2} N+t^{2} \sigma^{2}}$

حيث تثبير n إلى عدد أفراد العينة ، N إلى عدد أفراد المجتمع = بو مخبز،

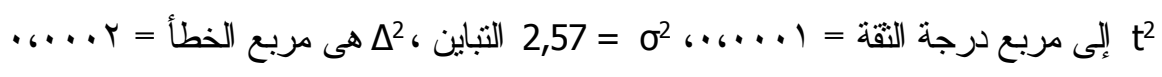

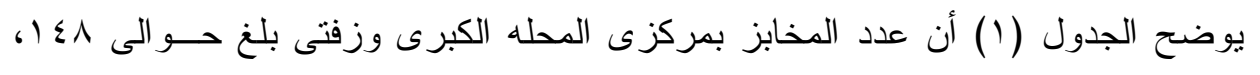

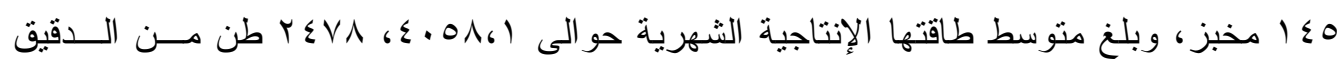

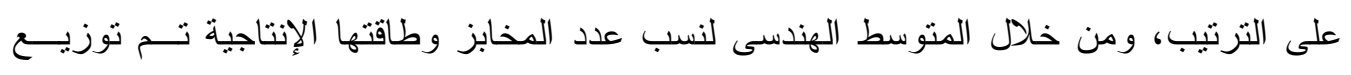

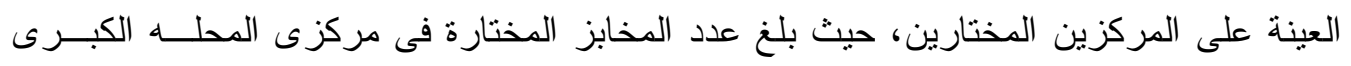

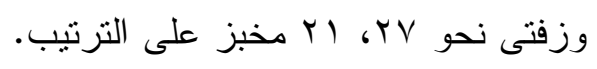


جدول (1) : عدد المخابز المختارة موزعه على المراكز بمحافظة الغربية عام ه 1 ـ ب

\begin{tabular}{|c|c|c|c|c|c|c|}
\hline \multirow{2}{*}{ عدد أفر اد } & \multirow{2}{*}{ الهندسى المعدل } & \multicolumn{2}{|c|}{ الطاقة الإنتاجية } & \multicolumn{2}{|c|}{ عدد المخابز } & \multirow{2}{*}{ المركز } \\
\hline & & $\%$ & طن & $\%$ & العدد & \\
\hline r & $07 ، \varepsilon$ & Tr. & $\left\{.0 \Lambda_{6}\right)$ & 0.60 & $1 \leqslant 1$ & المحله الكبرى \\
\hline r. & $\varepsilon r, 7$ & $r V . q$ & $r \leq Y \wedge$ & $\leqslant 9,0$ & $1 \leqslant 0$ & زفتى \\
\hline$\leq 7$ & $1 \ldots$ & $1 \ldots$ & 7047,1 & $1 \ldots$ & rar & الإجمالى \\
\hline
\end{tabular}

المصدر : مديريه التموين و التجارة الداخلية بمحافظة الغربية، إدارة الرقابه التموينية، ه 1 ـ؟؟.

مناقشة النتائج

أولاً : تصنيع الخبز المدعم

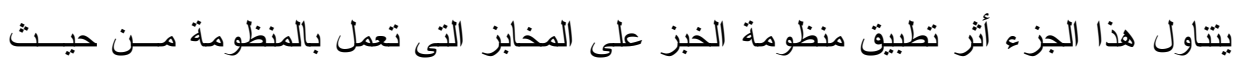

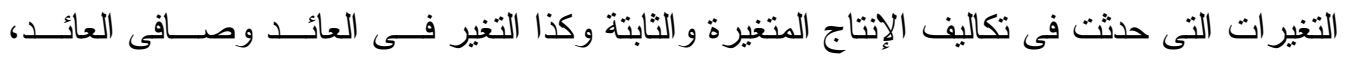

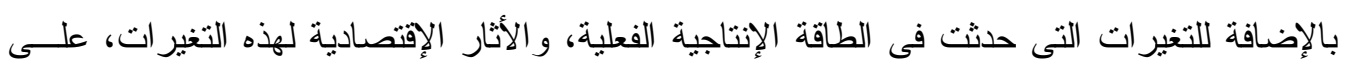

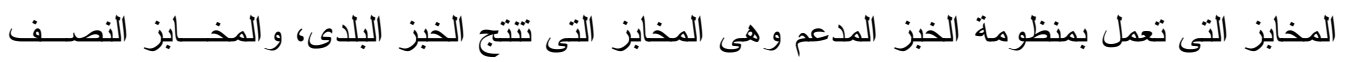

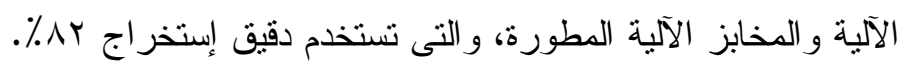

$$
\text { ا }
$$

تعتبر المخابز التى نتتج الخبز البلدى العادى هى أساس إنتاج الخبز وهذه المخابز تتسلم

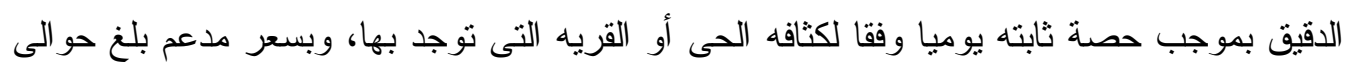

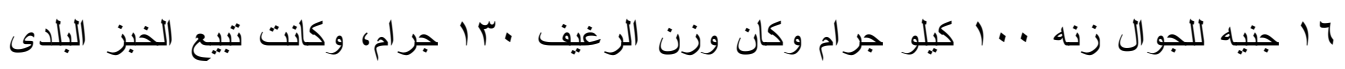

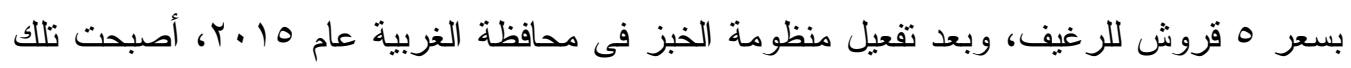

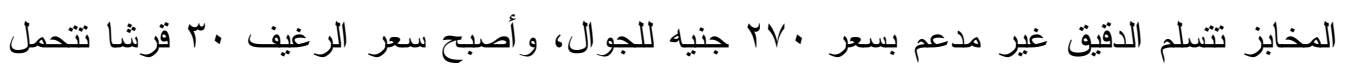

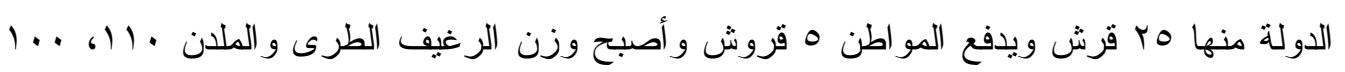
جرام. r - المخابز نصف الآلية : تتم فيها عمليه العجين و التقطيع و الفرد آليا كما تستخدم الدقيق كفرشه للخبز بديلاً للرده، وتتتج الخبز بنفس المواصفات الفنيه الموصى بها وتتسلم الدقيق بنفس سعر مثيلتها من المخابز التى تتتج الخبز البلدى المتفق عليه مع وزارة التموين.

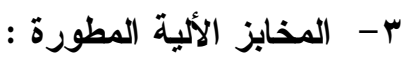

تتم فيها عمليه العجين و التقطيع و الفرد آليا، كما تتم فيها عملية التهويه آليا على سير ناقل للخبز ، كما تستخدم الدقيق كفرشه للخبز بديلا للرده، وتتتج الخبز بمواصفات فنيه مختلفة، وكانت

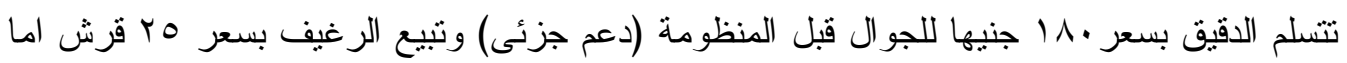


بعد المنظومة فان سعر الدقيق أصبح • rV جنيهاً للجو ال وتبيع الخبز بسعر •r قرشا للرغيف

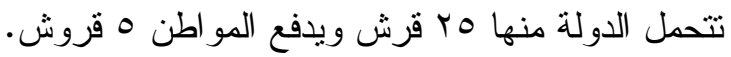

ثانياً: تكاليف تصنيع الخبز المدعم قبل وبعد تطبيق منظومة الخبز بمحافظة الغربية : أ- متوسط التكاليف و العائد من تصنيع الخبز المدعم بالمخابز البلاية :

يوضح الجدول (r) نكاليف تصنيع الخبز فى المخابز المنتجة للخبز البلدى فى محافظة الغربية قبل

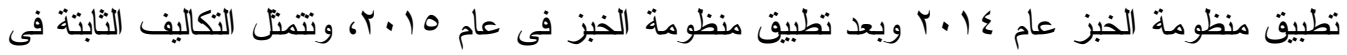
(تكلفة الفزصة البديلة) إهلاك رس المال و الذى نم حسابه بطريقه قسط الإهلاك الثابت، و الإيجار و الفائدة

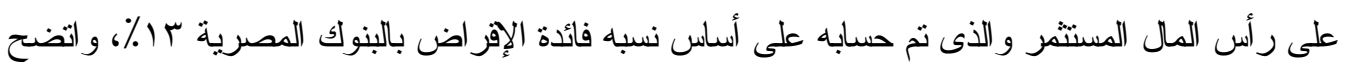

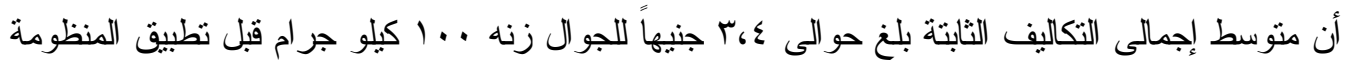

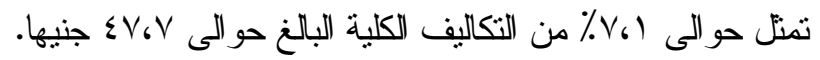

جلول (r) : متوسط تكاليف تصنيع الخبز المدعم من جوال زنه . . 1 كجم بالمخابز البلايه

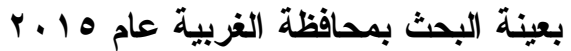

\begin{tabular}{|c|c|c|c|c|c|c|c|c|c|c|c|}
\hline \multirow{3}{*}{ الكالتكالية } & \multicolumn{5}{|c|}{ التكاليف المتغيرة بالجنيه } & \multicolumn{5}{|c|}{ التكاليف الثابتة بالجنيه } & \multirow{3}{*}{ المتغير ات } \\
\hline & \multicolumn{2}{|c|}{ الجملة } & \multirow{2}{*}{ مصروفات } & \multirow{2}{*}{ الدقيق } & \multirow{2}{*}{ العمال } & \multicolumn{2}{|c|}{ الجملة } & \multirow{2}{*}{ الإلجنيه } & \multirow{2}{*}{ رائدة } & \multirow{2}{*}{ إلهال } & \\
\hline & (*) $\%$ & جنيه & & & & $\left({ }^{(}\right) \%$ & جنيه & & & & \\
\hline$\varepsilon V_{6} V$ & 94.9 & $\varepsilon \varepsilon_{6} r$ & 11,1 & 17 & IVGr & $v_{6} 1$ & $\Gamma_{6} \varepsilon$ & . ^ & • & r.r & قبل المنظومة \\
\hline$r \leq \varepsilon ، 9$ & $9 \wedge, 1$ & rTh, T & rro & $r v$. & $\leqslant 0 ، \wedge$ & 1.9 & 7,7 & 1.9 & $1 ، \varepsilon$ & r.r & أثثاء المنظومة \\
\hline
\end{tabular}

(") النسبة المئوية من التكاليف الكلية، (**) المصروفات الأخرى : نتمل تكلفة الوقود والكهرباء و المياه

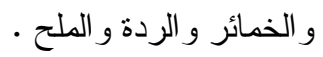
المصدر : بيانات عينة الدر اسة .

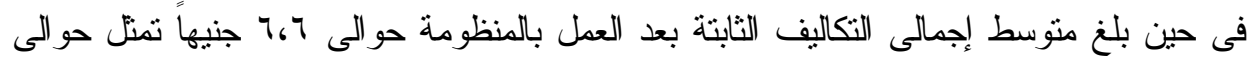

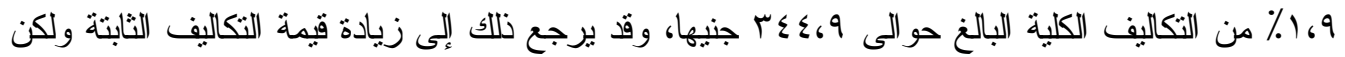
انخفصت نسبتها لزيادة قيمة التكاليف المتغيرة. وتتثمل التكاليف المتغيرة لإنتاج الخبز المدعم أجور العمالة، ثمن الدقيق و المصروفات الأخرى (ثمن الوقود، الكهرباء، المياه، الخمائر، الملح، النقل، اعمال الصيانه، الردة، و الإكر اميات)،

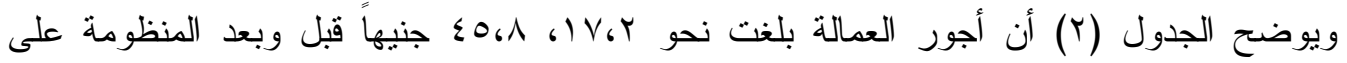
الترتيب، كما إرتفع ثمن جوال الدقيق من 17 إلى • rV جنيهاً على الترتيب، وبلغت المصروفات

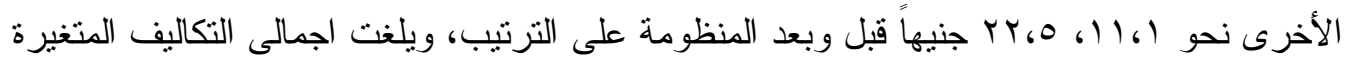

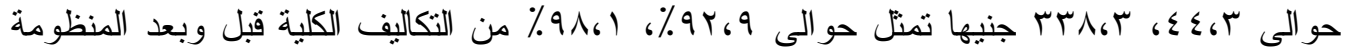
على الترتيب، وتنين إرتفاع جميع بنود التكاليف المتغيرة فى هذه المخابز بعد المنظومة عنه قبل 
المنظومة، ويرجع ارتفاع الاهمية النسبية للتكاليف المتغيرة بعد تطبيق المنظومة إلى إرتفاع سعر

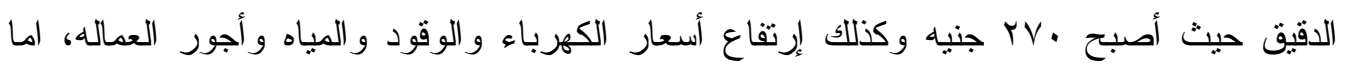
إنخفاض الأهمية النسبية للتكاليف الثابتة بعد المنظومة يرجع إلى إرتفاع التكاليف المتغيرة بعد

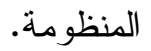
يشتمل العائد من تصنيع الخبز على قيمة الخبز الناتج وقيمة الســلـه (جميــع الخبـز غيـر المطابق للمو اصفات و لا يحظى برضى المستهلك فيتم تجميعه وبيعه بالكيلو جر ام ليقــدم للحيو انــات و الطيور بسعر نحو 0، 1 جنيه.

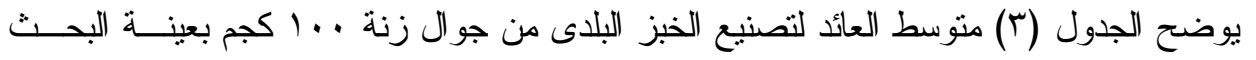

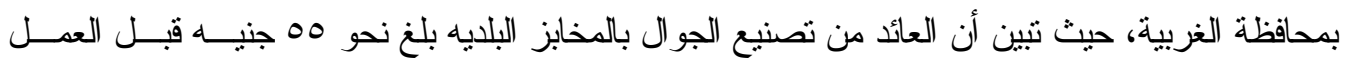

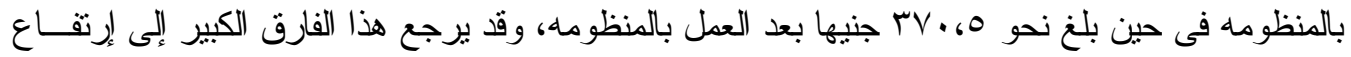

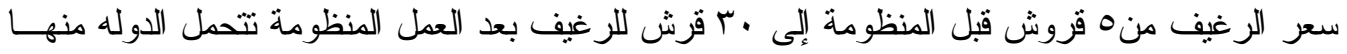

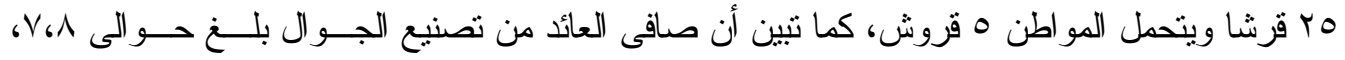

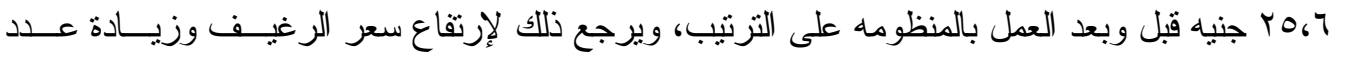

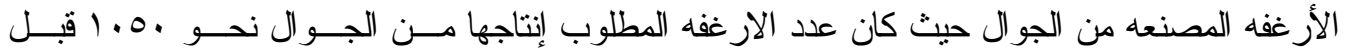

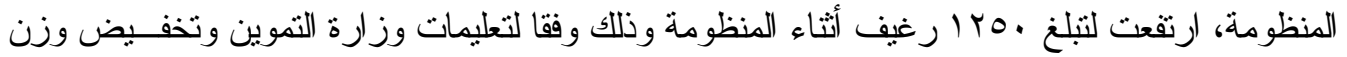

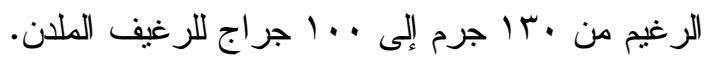

جدول (r) : متوسط العائد لتصنيع الخبز المدعم من جوال زنه . . 1 كجم بالمخابز البلايه

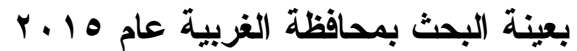

\begin{tabular}{|c|c|c|c|c|c|c|c|c|c|}
\hline صافى & & & & & \multicolumn{4}{|c|}{ العائد بالجنيه } & \multirow[b]{2}{*}{ المتغير ات } \\
\hline السنوى & للإدارة & العائد & الرغيف & الكلية & الإجمالى & السحله & \multicolumn{2}{|c|}{ الخبز } & \\
\hline \multirow{2}{*}{ ד. } & \multirow{2}{*}{7.9} & \multirow{2}{*}{$V_{6} r$} & \multirow{2}{*}{$\varepsilon, 0$} & \multirow{2}{*}{$\sum V_{6} V_{V}$} & \multirow{2}{*}{00} & r. & 1.0. & كمبه & قبل \\
\hline & & & & & & r.o & or.0 & قيمه & المنظومة \\
\hline \multirow{2}{*}{ NIrqr } & \multirow{2}{*}{$r \varepsilon_{6} r$} & \multirow{2}{*}{ Y0.7 } & \multirow{2}{*}{ rV.T } & \multirow{2}{*}{$r \leq \varepsilon 69$} & \multirow{2}{*}{$r V \cdot$. } & $\varepsilon \wedge$ & iro. & كميه & \multirow{2}{*}{ المنظومة } \\
\hline & & & & & & 9.9 & ד.6. & قيمه & \\
\hline
\end{tabular}

* العائد للإدارة = صافى العائد- الفائدة على رأس المال.

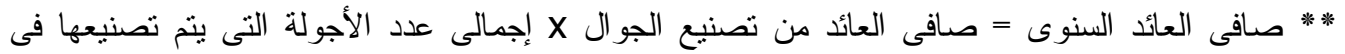

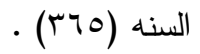
المصدر : بيانات عينة الدر اسة.

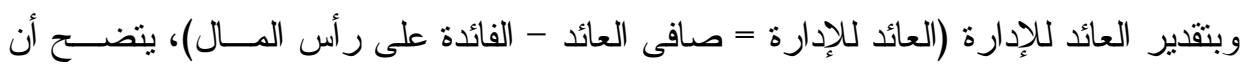

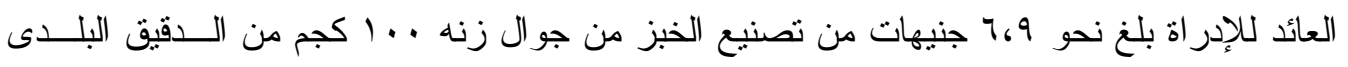

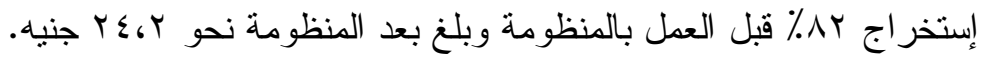


كما تبين أن صافى العائد السنوى لأصحاب المخابز التى نتتج الخبز البلدى المدعم قد بلغ حــو الىى

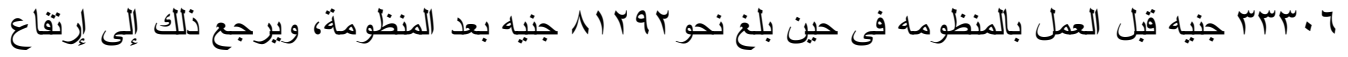

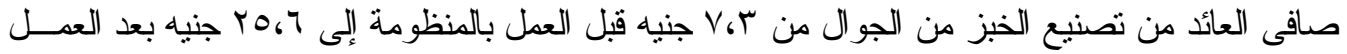

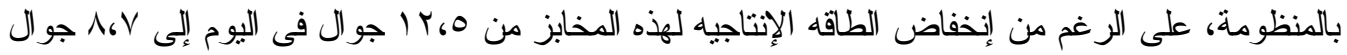

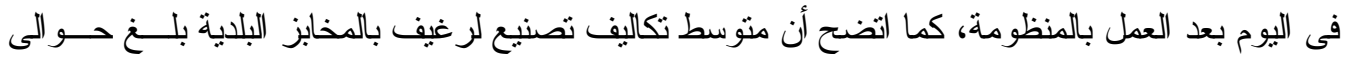

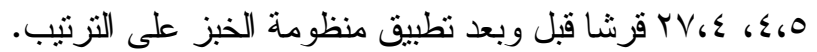

ب- متوسط التكاليف والعائد من تصنيع الخبز المدعم بالمخابز نصف الآلية بعينة البحث :

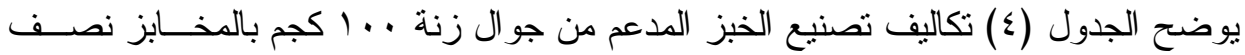

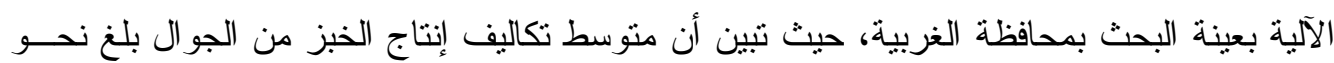

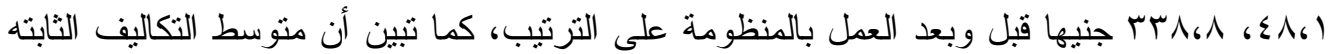

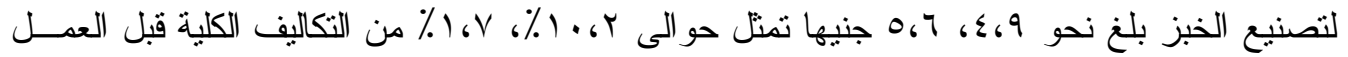

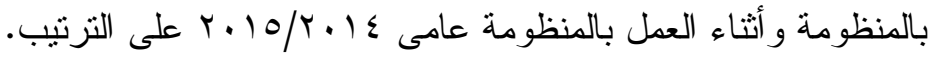

جدول (§) : متوسط تكاليف تصنيع الخبز المدعم من جوال زنه . . 1 كجم بالمخابز نصف الآلية

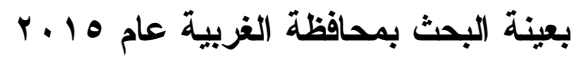

\begin{tabular}{|c|c|c|c|c|c|c|c|c|c|c|c|}
\hline \multirow{3}{*}{ الكالية الكاليف } & \multicolumn{5}{|c|}{ التكاليف المتغيرة بالجنيه } & \multicolumn{5}{|c|}{ التكاليف الثابته بالجنبه } & \multirow{3}{*}{ المتغير ا } \\
\hline & \multicolumn{2}{|c|}{ الجملة } & \multirow{2}{*}{ أخرى ("*) } & \multirow{2}{*}{ ثن } & \multirow{2}{*}{ جمال } & \multicolumn{2}{|c|}{ 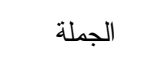 } & \multirow{2}{*}{ بالايجنيه } & \multirow{2}{*}{ رائدة } & \multirow{2}{*}{ إسلاك } & \\
\hline & $(*) \%$ & جنيه & & & & $(*) \%$ & جنيه & & & & \\
\hline$\left.\sum \Lambda_{6}\right)$ & $\wedge 961$ & $\sum T_{6} r$ & 11,9 & 17 & 10,4 & $1 \cdot 64$ & $\varepsilon, 9$ & .69 & 1,4 & $r_{6} \Lambda$ & المنظو مة \\
\hline 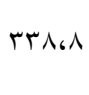 & $9 \wedge, 4$ & 促 & $Y 1,9$ & $r v \cdot$ & $\sum 1,4$ & $16 \mathrm{~V}$ & 0.7 & 1,5 & 1,4 & r.l & المنظومة \\
\hline
\end{tabular}

(") النسبة المئوية من النكاليف الكلية، (***) المصروفات الأخرى : نتمل تكلفة الوقود و الكهرباء و المياه

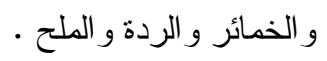

المصدر : بيانات عينة الدر اسة.

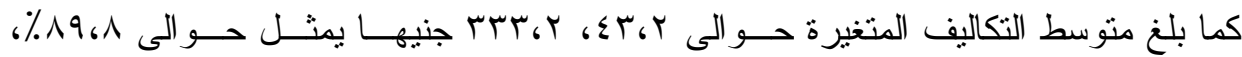

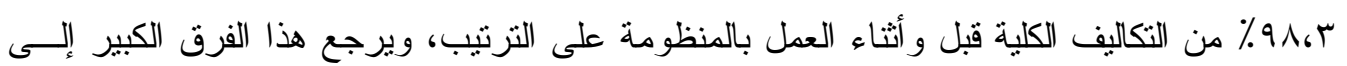

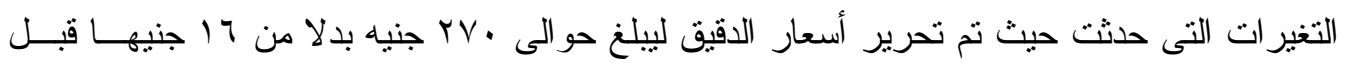
بالمنظومة، وإرتفاع أسعار الكهرباء و الوقود و المياه وأجور العماله بشكل كبير .

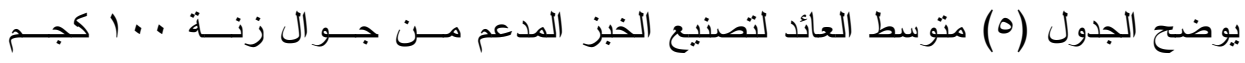

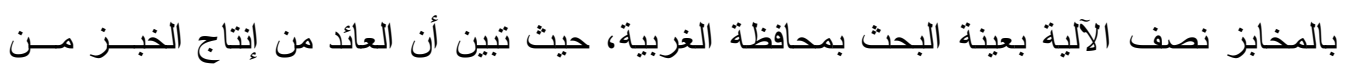

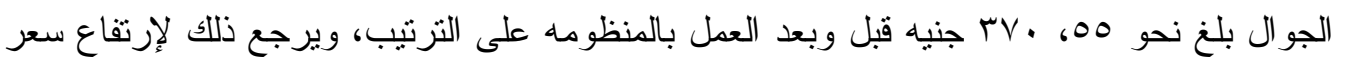


رغيف الخبز من ه قروش قبل المنظومة إلى •ب قرش بعد المنظومة، كما بلخ صافى العائُـــ نحسـو

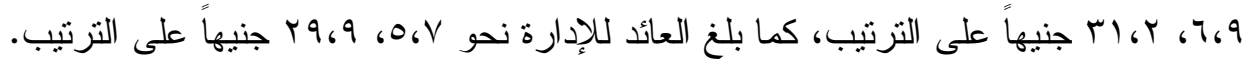

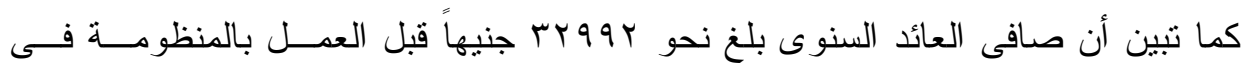

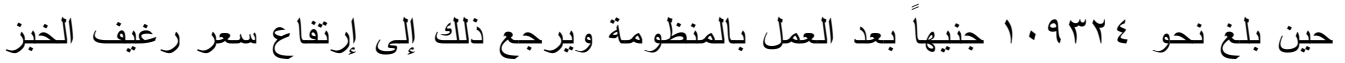

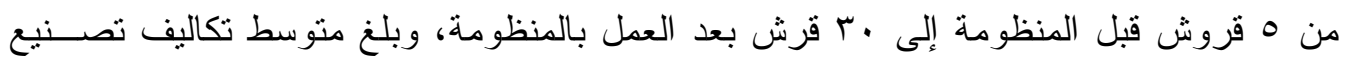

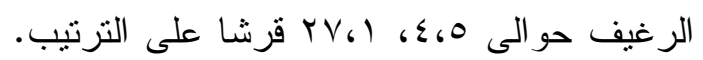

جدول (0) : متوسط العائد لتصنيع الخبز المدعم من جوال زنه . . 1 كجم بالمخابز نصف الآلية

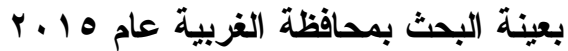

\begin{tabular}{|c|c|c|c|c|c|c|c|c|c|}
\hline \multirow{2}{*}{ العائد } & \multirow{2}{*}{ للإدارة } & \multirow{2}{*}{ بالجائدى } & \multirow{2}{*}{ بالر بلفة } & \multirow{2}{*}{ الكالجنيه } & \multicolumn{4}{|c|}{ العائد بالجنيه } & \multirow[b]{2}{*}{ المتغير ات } \\
\hline & & & & & الإجمالى & السحله & \multicolumn{2}{|c|}{ الخبز } & \\
\hline \multirow{2}{*}{ rrqqr } & \multirow{2}{*}{$0 . \mathrm{V}$} & \multirow{2}{*}{7.9} & \multirow{2}{*}{$\varepsilon$ «o } & \multirow{2}{*}{$\Lambda_{6}$} & \multirow{2}{*}{00} & $r$. & 1.0. & كميه & قبل \\
\hline & & & & & & r.O & Or.O & قبمه & المنظومة \\
\hline \multirow{2}{*}{$1.9 \pi Y \varepsilon$} & \multirow{2}{*}{$r 9.9$} & \multirow{2}{*}{ ri,r } & \multirow{2}{*}{ Y $\left.V_{6}\right)$} & \multirow{2}{*}{ 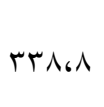 } & \multirow{2}{*}{$r v}$. & ro & IrTO & كميه & أثثاء \\
\hline & & & & & & r.o & TTV.0 & قيمه & المنظومة \\
\hline
\end{tabular}

المصدر : بيانات عينة الدر اسة . ل

\section{ج- متوسط التكاليف والعائد من تصنيع الخبز المدعم بالمخابز الآلية المطورة}

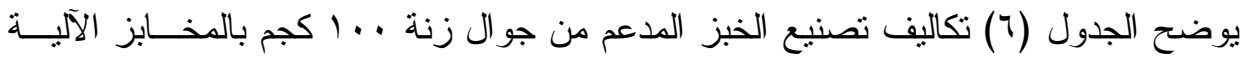

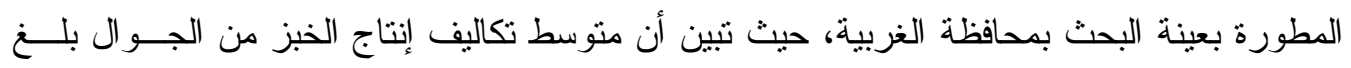

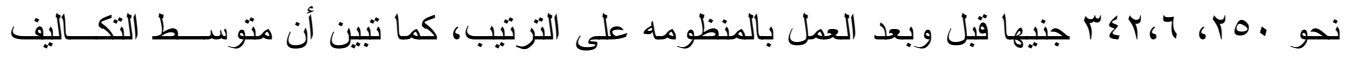

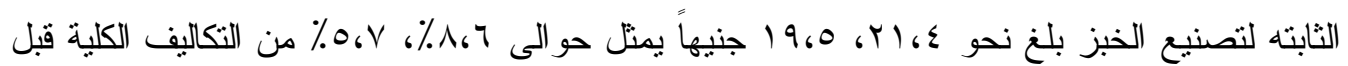

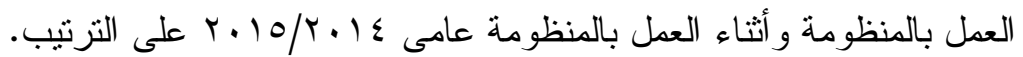

جدول (†) متوسط تكاليف تصنيع الخبز من جوال زنه . . . كجم بالمخابز الآلية المطورة

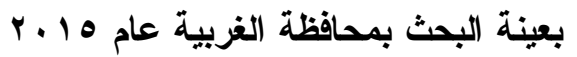

\begin{tabular}{|c|c|c|c|c|c|c|c|c|c|c|c|}
\hline \multirow{3}{*}{ الكالية } & \multicolumn{5}{|c|}{ التكاليف المتغيرة بالجنيه } & \multicolumn{5}{|c|}{ التكاليف الثابته بالجنيه } & \multirow{3}{*}{ المتغير ات } \\
\hline & \multicolumn{2}{|c|}{ الجملة ل } & \multirow{2}{*}{ 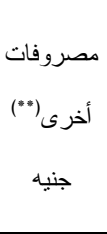 } & \multirow{2}{*}{ الدقيق } & \multirow{2}{*}{ جنيه } & \multicolumn{2}{|c|}{ 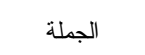 } & \multirow{2}{*}{ بالجنيه } & \multirow{2}{*}{ رأس الفائدة } & \multirow{2}{*}{ إسلاك } & \\
\hline & $\left({ }^{(}\right) \%$ & جنيه & & & & $\left({ }^{\circ}\right) \%$ & جنيه & & & & \\
\hline ro. & १1، ६ & KYA,T & ro,A & $1 \wedge$. & rYa & $\Lambda_{6} 7$ & r)، & 1، & r.A & IVGr & قبل المنظومة \\
\hline$r \leqslant r_{6} T$ & $9 \varepsilon_{6}$ & TrMGl & ro, & $r v$. & rY,o & $0 . V$ & 19.0 & 1,1 & r.V & $10, \mathrm{~V}$ & بعد المنظومة \\
\hline
\end{tabular}

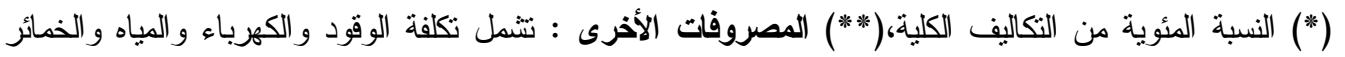




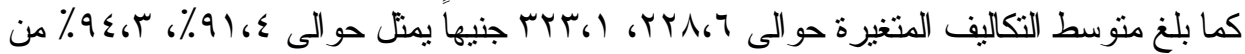
النكاليف الكلية قبل وأ ثثاء العمل بالمنظومة على التزتيب، ويرجع هذا الفرق الكبير إلى التغيرات التى حثت

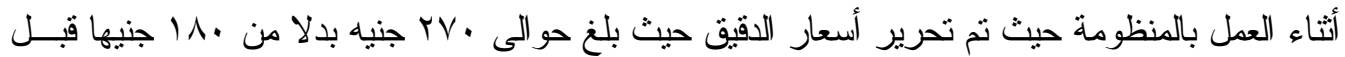
العمل بالمنظومة، كما إرتقعت أسعار الكهرباء و الوقود و المياه وأرتفعت أجور العماله بشكل كبير. يوضح الجدول (V) منوسط العائد لتصنيع الخبز من جو ال زنة . . 1 كجم بالمخابز الآلية المطورة بعينة البحث بمحافظة الغربية، حيث تبين أن إجمالى العائد من إنتاج الخبز بلغ نحو بآY، A

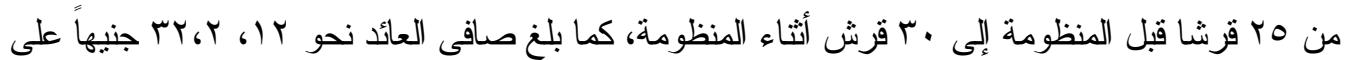

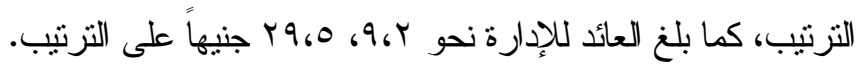
كما تبين أن صافى العائد السنوى بلغ نحو بr99؛ جنيهاً قبل العمل بالمنظومة ونحو

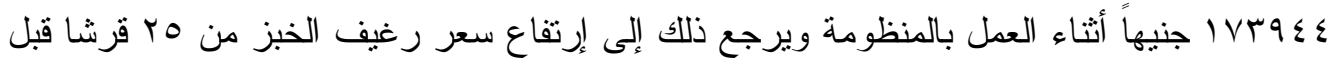
المنظومة إلى ·r قرشا أثناء العمل بالمنظومة وزيادة عدد الأجولة التى بسنطيع توزيعها فى اليوم و التى زادت من ء، 11 جوال لتصل الى 1، ــ جوال وذلك للاقبال الثديد على هذه النوعية من الخبز نظر الجودتها العالية وقابليتها للحفظ بدرجة أكبر من نوعية الخبز البلدى ونصف الآلى، وبلغ

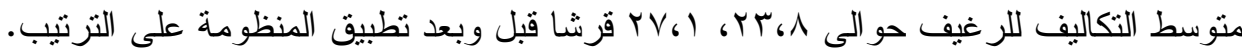

جدول (V) : متوسط العائد لتصنيع الخبز من جوال زنه . . 1 كجم من الدقيق بالمخابز الآلية

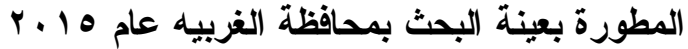

\begin{tabular}{|c|c|c|c|c|c|c|c|c|c|}
\hline صافى العائد & العائد & صافى & & التكاليف & \multicolumn{3}{|c|}{ العائد الكلى بالجنيه } & \multirow{3}{*}{\multicolumn{2}{|c|}{ المتغير ات }} \\
\hline السنوى & للإدارة & العائد & الر غيف & الكليه & \multirow{2}{*}{ الإجمالى } & \multirow{2}{*}{ السحله } & \multirow{2}{*}{ الخبز } & & \\
\hline بالجنيه & بالجنيه & بالجنيه & بالقرش & بالجنيه & & & & & \\
\hline \multirow{2}{*}{ ह9१४ } & \multirow{2}{*}{$96 r$} & \multirow{2}{*}{ ir } & \multirow{2}{*}{ A ג } & \multirow{2}{*}{ ro. } & \multirow{2}{*}{ rTY } & - & 1.0. & كميه & قبل ق ق \\
\hline & & & & & & - & rTY & قيمه & المنظو مة \\
\hline \multirow{2}{*}{ IVTq $\leq \varepsilon$} & \multirow{2}{*}{19,0} & \multirow{2}{*}{ MT, } & \multirow{2}{*}{ rV.l } & \multirow{2}{*}{$r \leqslant r_{6} T$} & \multirow{2}{*}{$r v \leqslant$ ऽ } & r & $\mid r \leqslant 1$ & كميه & أنثاء \\
\hline & & & & & & . ، & $r v \varepsilon$ ، & قيمه & المنظو مة \\
\hline
\end{tabular}

المصدر : بيانات عينة الدر اسة.

ثالثاً : سلوكيات اصحاب المخابز قبل وبعد تطبيق منظومة الخبز بمحافظة الغربية :

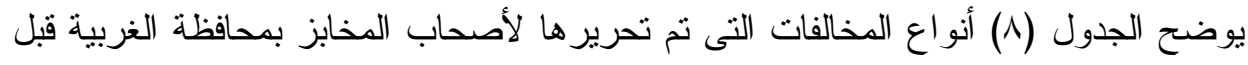

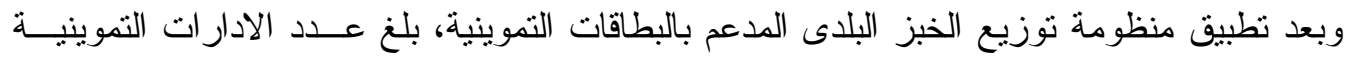

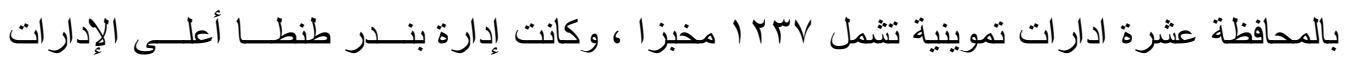

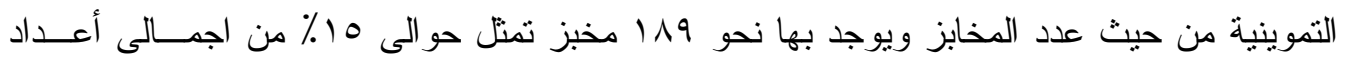

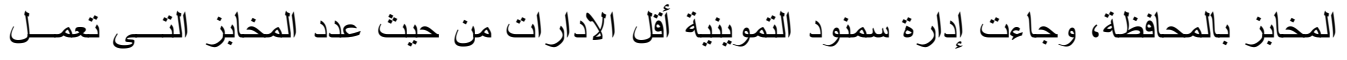
بالمنظومة والتى بلغت حو الى باج مخبز ا تمنل حو الى ه ٪ من اجمالى أعداد المخابز بالمحافظة. 
كما يوضح الجدول (^) ان اجمالى عدد المخالفات للمحررة لمخابز المحافظة بمختلف أنواعها بلغ

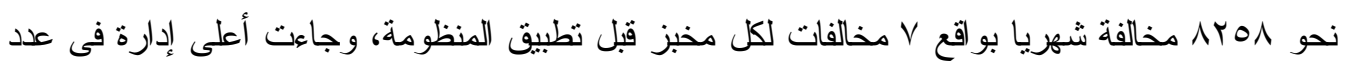
المخالفات لكل مخبز هى إدارة بسيون التموينية بواقع 1/ مخالفة لكل مخبز ، بينما جاءت أقل إدارة تموينية فى عدد المخالفات للمخابز إدارة للسنطة حيث بلغ منوسط عدد المخالفات ؛ مخالفات لكل مخبز شهرياً،

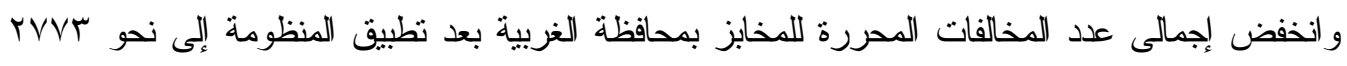

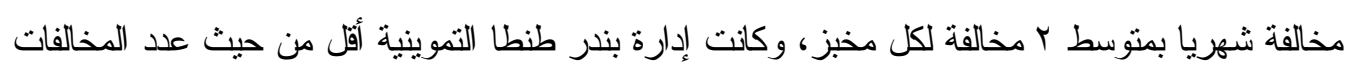

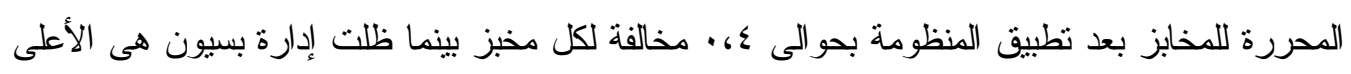
بمتوسط بلغ حوالى V مخالفات شهريا لكل مخبز وقد يعزى نلك إلى عدم الرقابة الجيدة فى ادارة بسيون. 


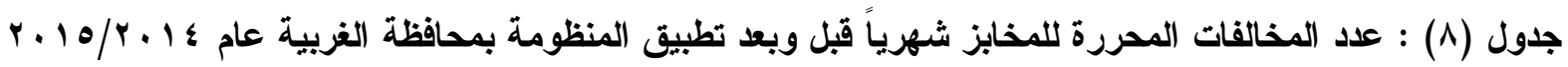

\begin{tabular}{|c|c|c|c|c|c|c|c|c|c|c|c|c|c|c|c|c|}
\hline \multicolumn{2}{|c|}{ جملة المخالفات } & \multicolumn{2}{|c|}{ اخرى } & \multicolumn{3}{|c|}{ بعد تطبيق المنظومة } & \multicolumn{2}{|c|}{ قبل تطبيق منظومة } & \multicolumn{6}{|c|}{ مخالفات مستمرة قبل وبعد تطبيق المنظومة } & \multirow{3}{*}{ المخابز } & \multirow{3}{*}{ 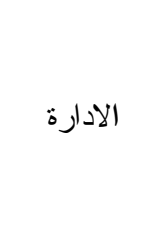 } \\
\hline \multirow[b]{2}{*}{ بعد } & \multirow[b]{2}{*}{ 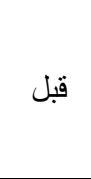 } & \multirow[b]{2}{*}{ بعد } & \multirow[b]{2}{*}{ قبل } & \multirow[b]{2}{*}{ توقف } & \multirow{2}{*}{ تلاعب فى ماكينة } & \multirow{2}{*}{ ذربى } & \multirow{2}{*}{ جزء من الحطاع } & \multirow{2}{*}{ تجميع } & \multicolumn{2}{|c|}{ تصرف } & \multicolumn{2}{|c|}{ نقص الوزن } & \multicolumn{2}{|c|}{ مو اصفات } & & \\
\hline & & & & & & & & & بعد & قبل & بعد & 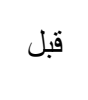 & بعد & قبل & & \\
\hline N & trt & - & r & - & $1 \varepsilon$ & 01 & 1 & r & 11 & ir & - & 197 & - & rio & 119 & بندر طنطا \\
\hline$r q$. & Art & Mr & $\wedge \vee$ & $1 T^{\prime}$ & ir & Vr & - & 0 & 9 & 01 & rA & 纟l & r. & ror & $1 \leq 7$ & مركز طنطا \\
\hline 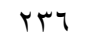 & $10 . r$ & 77 & $r$. & 0 & r & 11 & $\varepsilon$ & 7 & v & rA & 71 & $71 \leq$ & or & $\Delta r$. & $1 \leqslant 9$ & بندر المحله \\
\hline rrs & רז' & $\vee \wedge$ & 77 & $\wedge$ & r) & $\varepsilon r$ & - & 0 & ir & $1 \pi$ & 19 & $r .9$ & $V V$ & $\varepsilon \varepsilon r$ & $1 \leqslant 1$ & مركز المحله \\
\hline 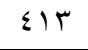 & $T \vee \wedge$ & 100 & r & 11 & - & $0 \wedge$ & - & - & - & - & v) & rqr & 111 & rat & 91 & قطور \\
\hline $10 \mathrm{~V}$ & $V \cdot r$ & or & $\leq 0$ & - & $r$ & ir & 9 & 1. & $\varepsilon$ & $\varepsilon$ & $\leq 7$ & ror & ro & rNT & Tr & سمنود \\
\hline$\leqslant 11$ & $1 \cdot 1$. & $19 \varepsilon$ & $\varepsilon$. & - & - & 11 & - & - & - & 1. & VT & $7 \ldots$ & $7 \varepsilon$ & $\varepsilon r$. & 7. & بسيون \\
\hline rq. & אזד & 71 & 10 & $1 \varepsilon$ & 9 & 19 & - & $r$ & $1 \pi$ & 17 & NT & $r \cdot \varepsilon$ & 00 & roo & $11 \pi$ & كفر الزيات \\
\hline Tr & 0.1 & 97 & $\varepsilon V$ & ro & 10 & rV & - & 7 & 7 & ir & $V \varepsilon$ & $10 \leqslant$ & 79 & $r \wedge \Lambda$ & 110 & السنطة \\
\hline 174 & ᄉr. & $\varepsilon r$ & rV & $1 \pi$ & 9 & $r \wedge$ & $1 T$ & 17 & $r \varepsilon$ & r & rI & $r \leq \varepsilon$ & rT & rav & $1 \leq 0$ & زفتى \\
\hline rVVT & NYON & Av 9 & $\leqslant \wedge 7$ & rir & 117 & $\leqslant 19$ & $r v$ & or & $\wedge 7$ & $1 \wedge$. & $0 \leqslant \leqslant$ & ro9V & $01 \mathrm{~V}$ & 1910 & ITHV & الاجمالى \\
\hline $1 \cdots$ & $1 \ldots$ & MI.V & 0.9 & $v_{6} 7$ & $\varepsilon_{6} r$ & 10,1 & r & .67 & r.l & r. & 19.7 & $\varepsilon r_{6} T$ & 11167 & $\varepsilon V_{6} \varepsilon$ & بالفات & \% من جملة \\
\hline
\end{tabular}

المصدر: مديرية التموين و التجارة الداخلية بمحافظة الغربية، ادارة الرقابة، بيانات غير منشورة 
يوضح الجدول (^) أن هناك مخالفات استحدثت بعد تطبيق المنظومة ومخالفات تلاشت بعد النطبيق، و هنالك مخالفات مستمرة قبل وبعد تطبيق المنظومة وفيما يلى عرض لتلاك المخالفات.

1 - المخالفات التى تلاشت بعد تطبيق المنظومة أ- الخلل فى تصنيع الحصة المقررة للمخبز من الاقيق وعدم استخدامه فى إنتاج الخبز حيث كان

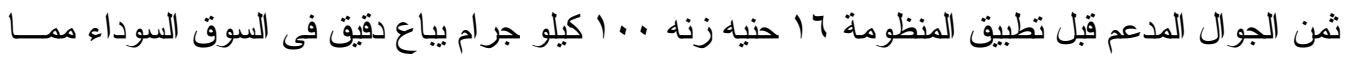

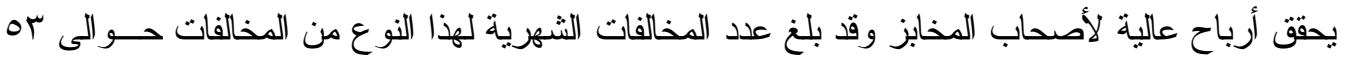

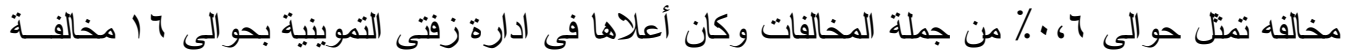
شهرياً. ب- استقطاع جزء من الحصة : المنصرفة وعدم استخدامه فى انتاج الخبز وبيعه فــى الســوق

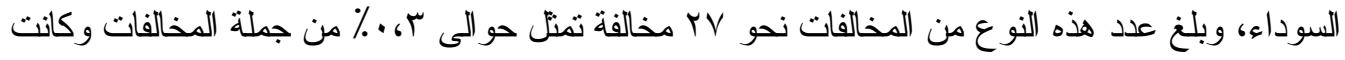

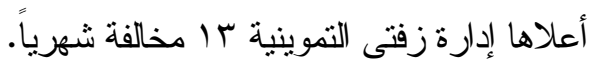

r - مخالفات استحدثت بعد تطبيق المنظومة

أ- - الكارت الذهبى : حيث يخصص لمخابز معينة تقع فى مناطق التجمعات و التى فى الغالب تتشل أفراد لهم ظروف خاصة كالمغتربين لا تتيح لهم صرف الخبز بالبطاقة التموينية، وهذا الكارت الذهبى يتيح

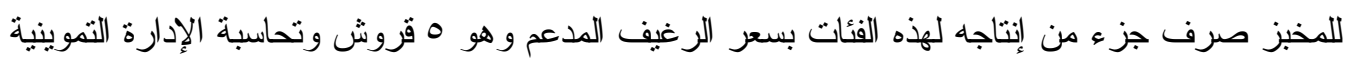
بالسعر المنصرف بالبطاقة وهو مب قرشا، وقد ثبت عدم جدية المخابز و إستغلالها لهذه الحصده إبــتغلال

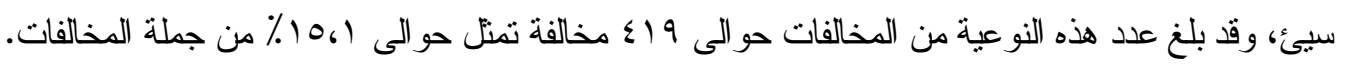
ب- التلاعب فى ماكينه الصرف المخصصة للمخبز : بحيث تؤدى إلى صرف نقاط خبز غير حقيقية (و همية) لم يتم إنتاجها بالمخبز فعلياً وقد نم اكتشاف هذه المخالفات نتيجة مر اجعــه الكميـات

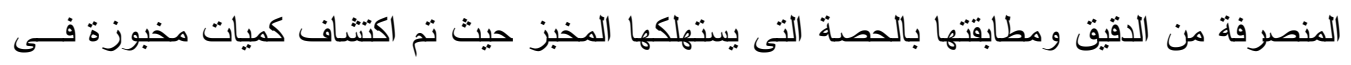

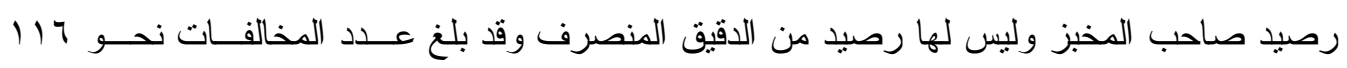

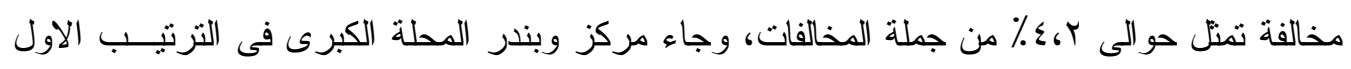
و الثانى من حيث عدد المخالفات على النزتيب.

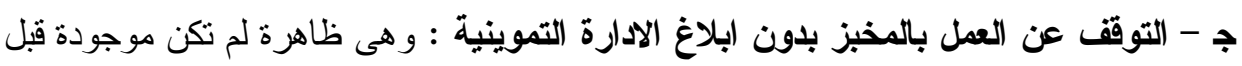

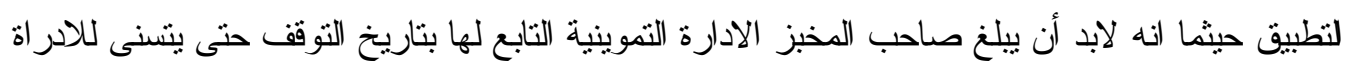

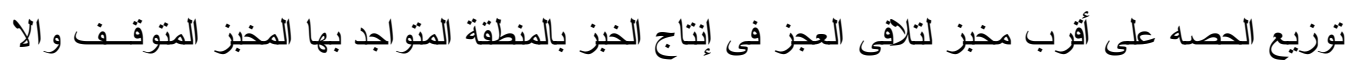

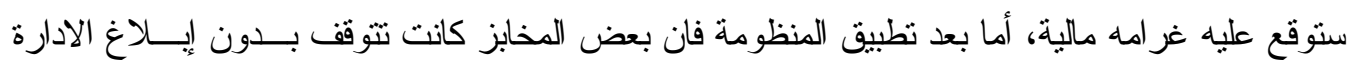

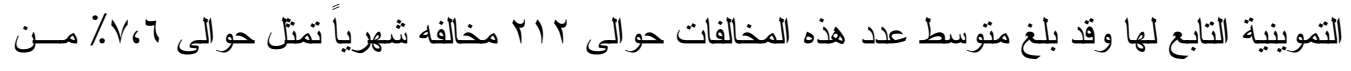

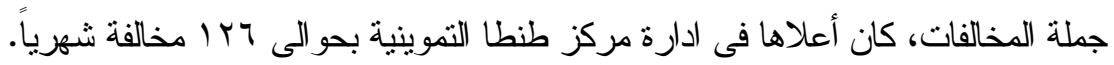




\section{r- المخالفات المستمرة قبل وبعد تطبيق المنظومة}

أ- التلاعب فى مواصفات الرغيف : وتنين أن متوسط عدد مخالفات التلاعب فى مواصفات الرغيف

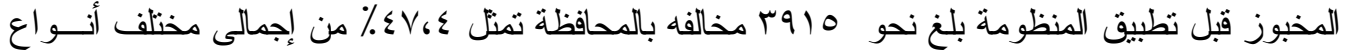

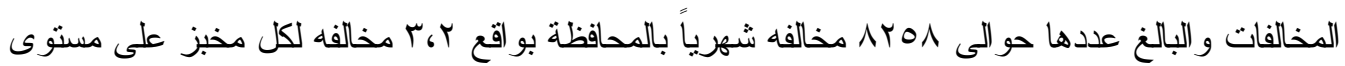
المحافظة شهرياً، وانخفض إجمالى عدد المخالفات فى مو اصفات الخبز بالمحافظة ليبلغ حو الى ل V Vخالفه

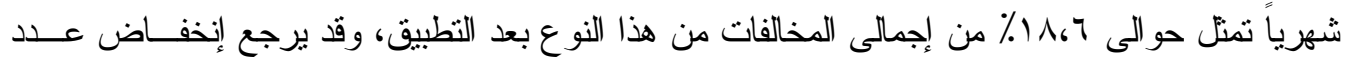
المخالفات فى مواصفات الخبز بعد نطبيق المنظومة إلى تحسين نوعيه الرغيف المنتج نتيجه نتافس المخابز فى تحسين نوعيه الاتتاج لتسجيل أعلى عدد من الخبز الموزع حتى تحقق نسبه عالية من الربح.

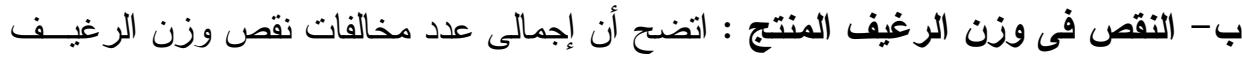

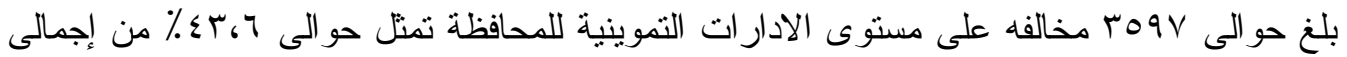

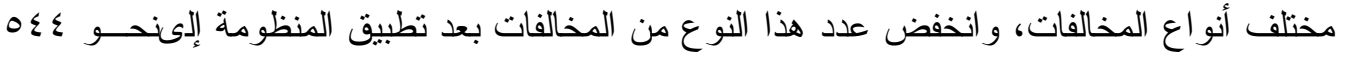
مخالفه شهريا تمنل نحو 9 19 1\% من من إجمالى مختلف أنواع المخالفات بعد النطبيق. ج- التصرف فى الحصه من الاقيق فى غير الغرض المخصص لها : تنين أن عدد المخالفات هذا

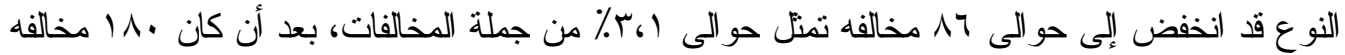

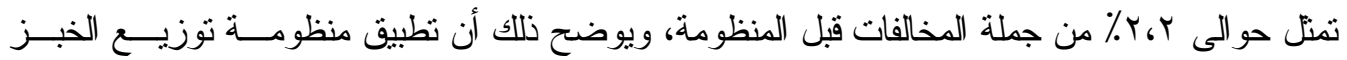
بالبطاقات التموينية أدى بوجه عام إلى انخفاض عدد المخالفات وظهور التتافس بين المخابز فى انتاج رغيف خبز مقبول للمستهلك وكانت بوجه عام فى صالح المستهلك و وأصحاب المخابز .

رابعاً : المؤشرات الاقتصادية لتصنيع الخبز المدعم قبل وبعد تطبيق منظومة بمحافظة الغربية تتمثل تلك المؤشر ات الاقتصادية فى التكاليف و العائد من تصنيع جوال من الدقيق زنة ـ. كيلو جر ام لكل نوع من انواع المخابز الثلاثة، بالاضافة لصافى العائد والعائد للادارة و الطاقة الانتاجية أو التصنيعية، حيث يوضح الجدول (9) أثز نطبيق منظومة الخبز على اصحاب المخابز و أهم المؤشر ات الاقتصادية لمختلف أنو اع المخابز قبل وبعد تطبيق المنظومة والتى تتمنل فى : أ- تكاليف تصنيع الجوال : ييين الجدول (9) نكاليف تصنيع جوال الدقيق زنه . . 1 كجم

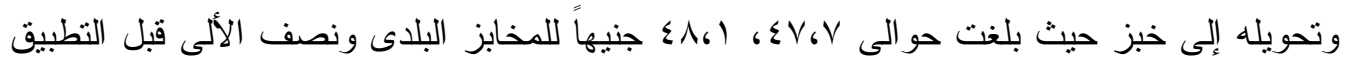
حيث يتسلها الدقيق بالسعر المدعم المقدر بحو الى 17 جنيهاً للجو ال، بينما بلغت تلك التكاليف بالنسبة

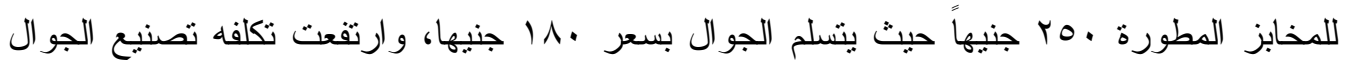

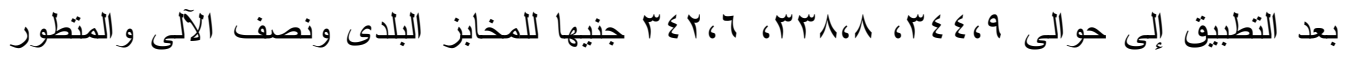

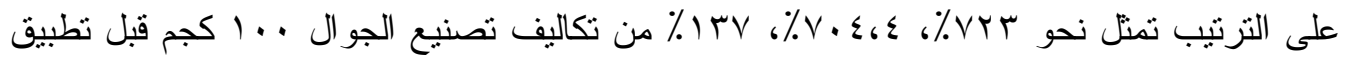

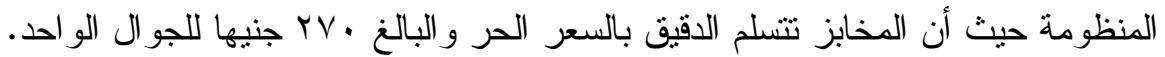

ب- إجمالى العائد من تصنيع الجــوال : يشتمل العائد من تصنيع الخبز على قيمة الخبز

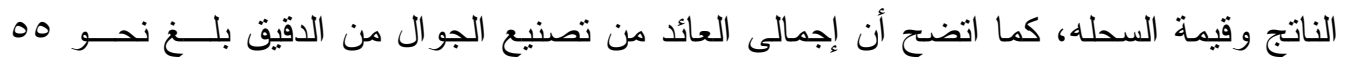

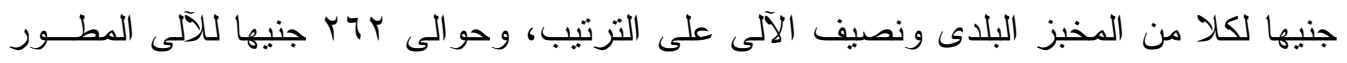




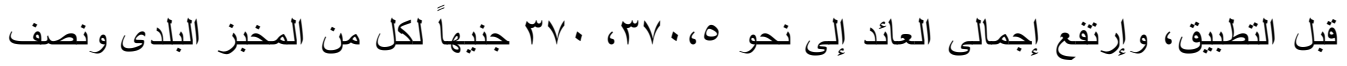

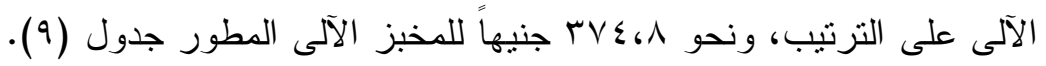
جدول (9) : أهم المؤشرات الاقتصادية لتطبيق منظومة الخبز للمخابز بمحافظة الغربية

عام 10

\begin{tabular}{|c|c|c|c|c|c|c|}
\hline \multicolumn{3}{|c|}{ 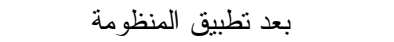 } & \multicolumn{3}{|c|}{ قبل تطبيق المنظومة } & \multirow{2}{*}{ المتغير ات } \\
\hline 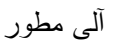 & نصف الآلى & 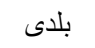 & آلى مطور & نصف الآلى & 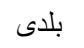 & \\
\hline$r \leq r_{6} T$ & rr人, & $r \leq \varepsilon ، 9$ & ro. & $\left.\sum \wedge_{6}\right)$ & $\sum V_{6} V$ & تكاليف تصنيع جو ال ـ ـ ا كجم الجنيه \\
\hline$r V \varepsilon, \Lambda$ & 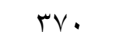 & $r V_{0}, 0$ & rTt & 00 & 00 & عائد تصنيع جو ال . . 1 كجم بالجنيه \\
\hline rts & ri,r & ro, T & ir & 7.9 & $V_{6} r$ & صافى العائد لتصنيع جو ال . . ا كجم بالجنيه \\
\hline$r 9,0$ & $r 9,9$ & $r \varepsilon_{6} r$ & $96 r$ & $0 . \mathrm{V}$ & 7.9 & عائدالادارة لتصنيع جو ال . . ـ كجم بالجنيه \\
\hline $1 \varepsilon_{6} \wedge$ & 9.7 & $\Lambda_{6} \mathrm{~V}$ & $11 ، \varepsilon$ & 14,1 & $1 r_{6} 0$ & متوسط الحصة الانتاجية جو ال/ يوم \\
\hline $1 V r 69$ & 1.964 & N1, r & $\leq 9,9$ & rr.q9 & 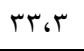 & صافى العائد السنوى بالالف جنيه \\
\hline $1096 \varepsilon$ & $1 \cdot \varepsilon_{6} \wedge$ & $V \nearrow ، \Lambda$ & r忪r & tratr & r.o & عائدالادارة السنوى بالالف جنيه \\
\hline .617 & $r_{6} . \varepsilon$ & r،八 & - & 1.9 & r.9 & نسبة أعداد الارغفة الرديئة ٪ \\
\hline r & $r$ & $\varepsilon$ & r & v & 9 & متوسط عدد المخالفات الثهرية \\
\hline
\end{tabular}

المصدر : بيانات عينة الدراسة .

ج- صافى العائد من تصنيع الجوال : يساوى الفرق بين العائد الكلى و التكاليف الكلية حيث بلغ

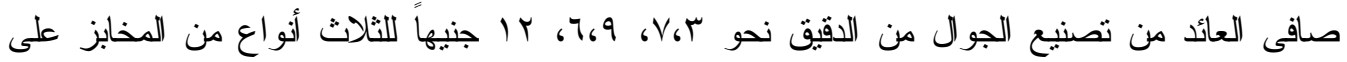

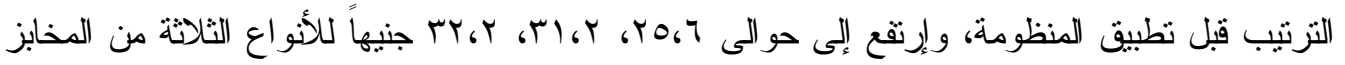

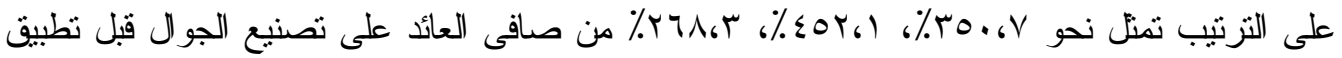

د- عائد الادارة من تصنيع الجوال : يساوى عائد الإدارة من تصنيع الجوال الفرق بين

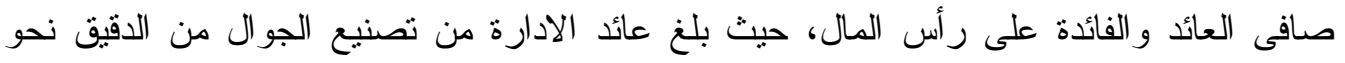

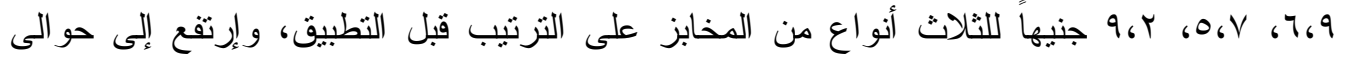

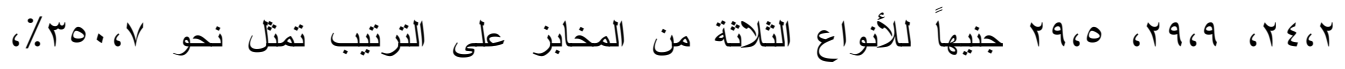

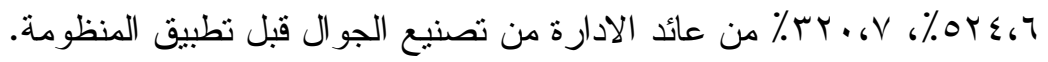

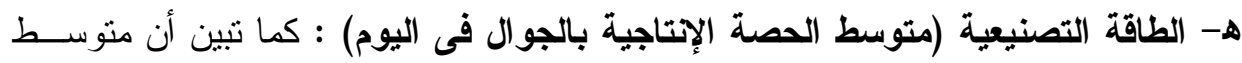

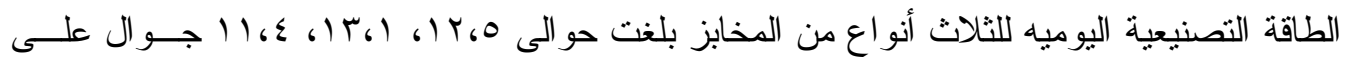

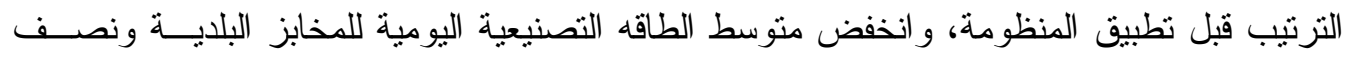

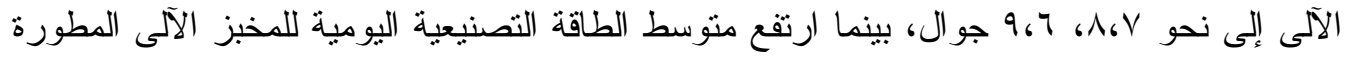

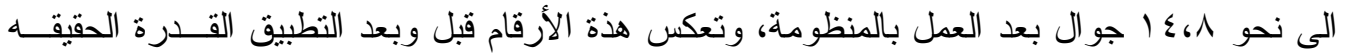

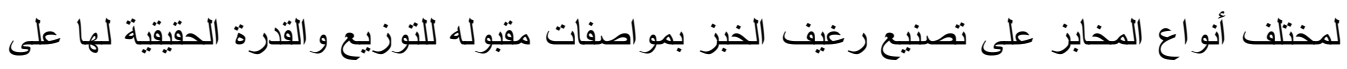

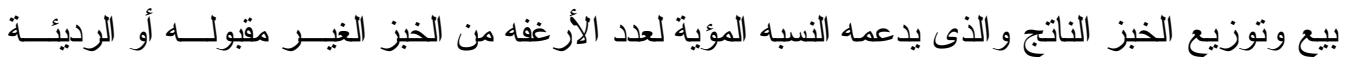


و- صافى العائد السنوى : يساوى صافى العائد السنوى صافى العائد من تصنيع الجوال مضروب فى إجمالى عدد الأجولة التى يتم تصنيعها فى السنه، حيث نبين ارتقاع صافى العائد السنوى

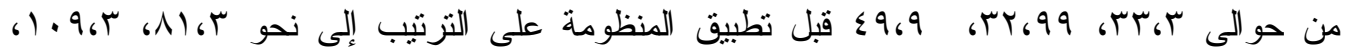


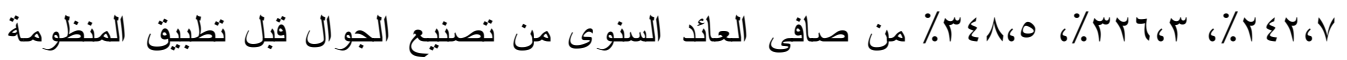

جدول (9).

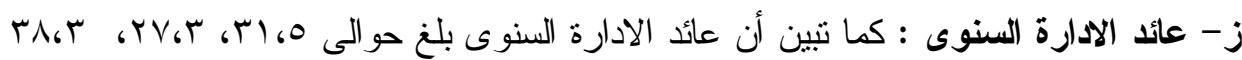

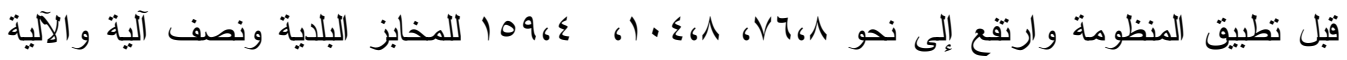

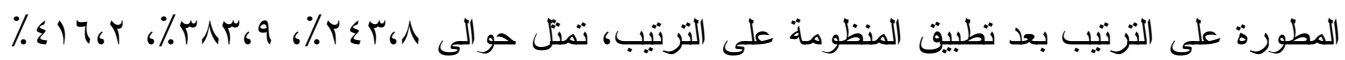
من عائد الادارة السنوى من تصنيع الجو ال قبل تطبيق المنظومة.

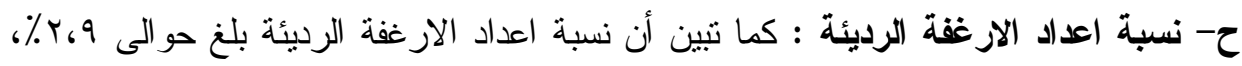

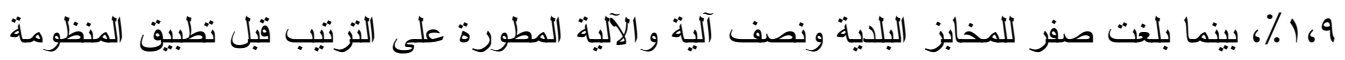

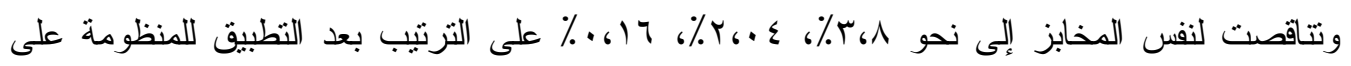
التزتيب.

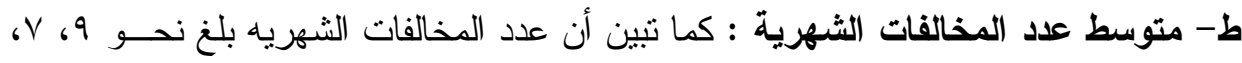

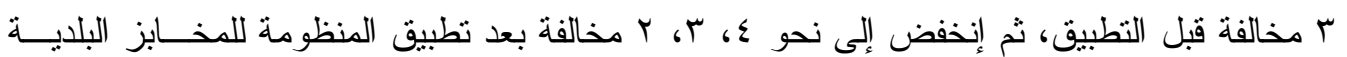
ونصف آلية والآلية المتطورة على التزنيب.

خامساً : المشاكل التى تواجه أصحاب المخابز بعد تطبيق منظومة الخبز بمحافظة الغربية

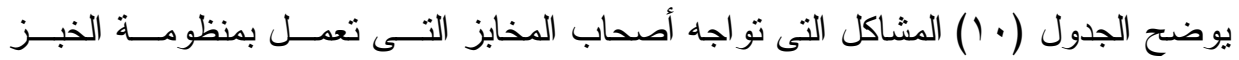

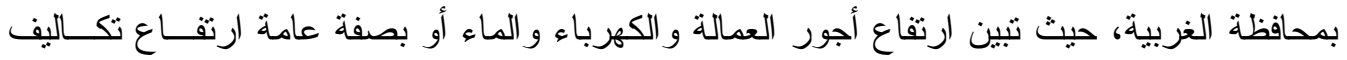

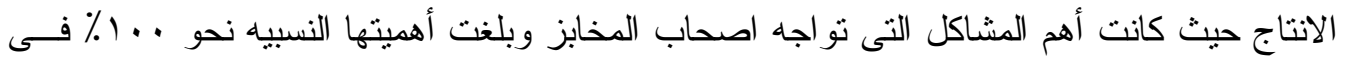

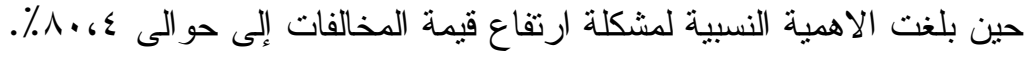
جدول ( • 1) : أهم المشاكل التى تواجه أصحاب المخابز بعد تطبيق منظومة الخبز

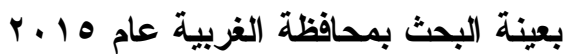

\begin{tabular}{|c|c|c|}
\hline$\%$ & التكر ار & 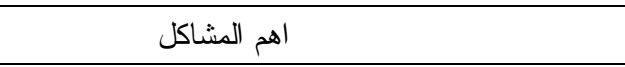 \\
\hline $1 \cdots$ & $\leqslant 7$ & ارتفاع اجور العمالة و الكهرباء والماء (ارتفاع التكاليف) \\
\hline ^.، & rV & 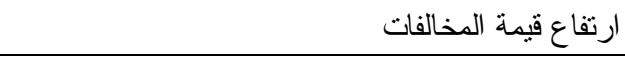 \\
\hline v4.1 & ro & انخفاض الطاقة الانتاجية \\
\hline 7.69 & rA & تعطل ماكينة صرف وضعف شبكة الانترنت \\
\hline$\leqslant r$ ، 0 & $r \cdot$ & انخفاض جودة الدقيق \\
\hline$\leqslant r$ ، 0 & $r \cdot$ & انقطاع التيار الكهربائى \\
\hline rฯ, & ir & ثنقى كمية من الخبز دون نوزيع على البطاقات \\
\hline $1 \ldots$ & $\leq 7$ & اجمالى افر اد العينة إن \\
\hline
\end{tabular}

المصدر : بيانات عينة الدر اسة. 


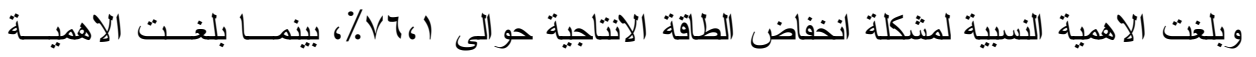

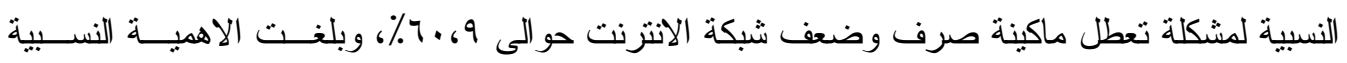

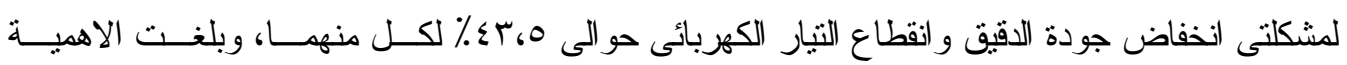

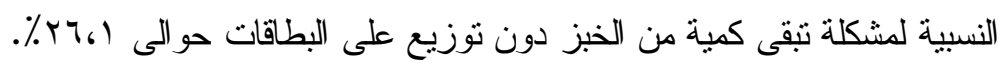

1أحمد محمد مندور (دكتور)، واخرون، الإقتصاد الجزئى، قسم الإقتصاد، كلية التجارة، جامعة

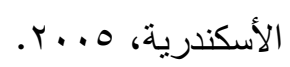

ץ- صابر سيد أحمد ياسين (دكتور)، محاضرات فحى العينات والمستح الاحصائى، قمم الإقتصاد

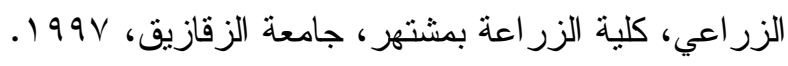

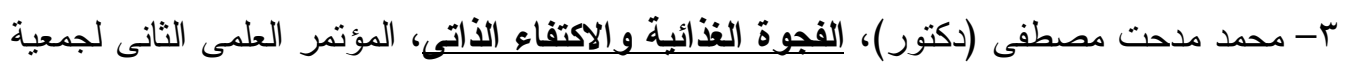

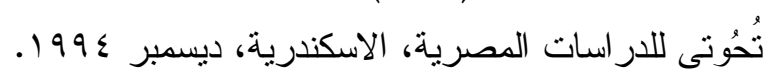

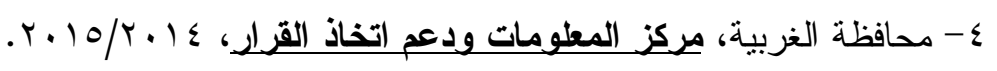

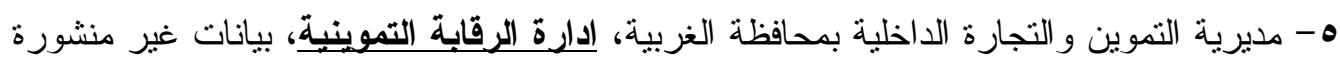
. $10 / r \cdot 1 \leq$

צ- وزارة الزراعة واستصلاح الأراضى، قطاع الثؤن الاقتصادية، نشرة الاقتصاد الزراعى، \&. V - وزارة الزراعة واستصلاح الأراضى، قطاع الثؤن الاقتصادية، نشرة المبزان الغذائى، .$+1 \varepsilon$

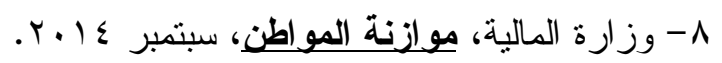

9- معهد بحوث الاقتصاد الزر اعى، قسم بحوث الدراسات الاقليمية، دراسة اقتصادية ميدية ميدانية لمنظومة الخيز المدعم في جمهورية مصر العربية (در اسة حالة بمحافظة الغربية)، 17 ـــ. 